\title{
I mplementasi Counter Production Monitoring pada Mesin Tekstil berbasis Mikrokontroler
}

\author{
HENDI HANDI AN RACHMAT, HARI ANDI ASRI L \\ Teknik Elektro Institut Teknologi Nasional Bandung \\ Email :hendi.hr@gmail.com
}

\begin{abstract}
ABSTRAK
Sistem Counter Production Monitoring (CPM) diimplementasikan untuk menghitung secara otomotis kecepatan mesin, kecepatan produksi, dan jumlah produksi.Sistem ini digunakan pada mesin pemintal benang di industri tekstil untuk mengetahui efisiensi kerja mesin dan hasil produksi benang. Sistem terdiri dari perangkat keras dan lunak berbasis mikrokontroler dan personal komputer (PC) untuk mengukur putaran mesin guna menghitung ketiga besaran hasil produksi. Inductive proximity sensor dan encoder gear dipasang dengan jarak $1 \mathrm{~mm}$ pada shaft mesin yang berputar untuk mendeteksi jumlah putaran mesin berdasarkan jumlah pulsa yang dideteksi oleh sensor selama durasi tertentu. Mikrokontroller menghitung tiga besaran produksi dan menampilkan hasil pada display LCD melalui pengaturan 3 buah tombol serta mengirimkan ke PC melalui komunikasi serial untuk ditampilkan. Hasil pengujian selama 3 hari menunjukkan terjadi perbedaan antara sistem CPM dan perhitungan manual (Tachometer) yaitu antara 0.35-0.4 HANK.Perbedaan terjadi karena pada perhitungan manual, mesin diasumsikan selalu berjalan. Padahal pada kenyataannya terjadi proses dopping (penggantian cone benang). Dapat disimpulkan bahwa sistem CPM telah dapat digunakan untuk mengetahui efisiensi kerja mesin dan hasil produksi secara otomatis.
\end{abstract}

Kata kunci: counter production monitoring, encoder gear, Inductive Proximity Sensor, mikrokontroler, personal komputer.

\begin{abstract}
A Counter Production Monitoring (CPM) system was implemented to calculate automatically a machine speed, a production speed and a total production. This system was employed on a spinning machine in a textile industry to know machine efficiency and a number of thread productions. The system consists of some microcontroller-based hardware and software modules to detect machine rotation. Inductive proximity sensor and encoder gear were installed with a rotary machine shaft in $1 \mathrm{~mm}$ distance. A number of machine rotation was calculated from the number of pulses that detected by sensor for a certain time duration. Microcontroller calculated three production values and displayed on LCD by controlling three different push buttons. Subsequently, the data transferred to PC via serial communication to be displayed on PC. From three days testing, the system showed a different result of 0.35 0.4 HANK total production between CPM system and manual procedure using Tachometer. The different was due to the machine was assumed still working during dopping (change thread cone) process in the manual procedure. As a conclusion, CPM system can be used to know the machine efficiency and the number of thread production automatically.
\end{abstract}

Keywords: counter production monitoring, encoder gear, Inductive Proximity Sensor, microcontroller, personal computer. 
Rachmat, dkk

\section{PENDAHULUAN}

Perangkat monitoring produksi yang bersifat elektronik seperti pada suatu industri tekstil diperlukan untuk memberikan informasi performa kerja baik karyawan maupun mesin.Perangkat monitoring yang dikenal juga sebagai Counter Production Monitoring (CPM) ini berfungsi memonitor performa kerja berdasarkan kecepatan mesin.Dengan melihat hasil pengukuran dari perangkat ini, maka dapat dipantau dan diketahui pencapaian suatu target produksi.

Akan tetapi peralatan monitoring sejenis ini relatif sulit ditemukan di pasaran lokal dan jika pun ada, harganya pun akan relatif mahal. Hal ini membuat industri tekstil lokal terutama industri pemintal benang dengan skala relatif kecil relatif sulit untuk memiliki alat sejenis ini. Tachometer seringkali kali digunakan untuk mendeteksi putaran motor, seperti industri tekstil lokal masih menggunakan Tachometer genggam untuk menghitung putaran mesin. Dalam studi sebelumnya, (Hidayat dkk, 2014) Tachometer digunakan untuk mendeteksi putaran motor induksi 1 phasa. Akan tetapi, pada umumnya Tachometer yang digunakan masih bersifat manual. Begitu pula pada industri tekstil, sehingga proses monitoring produksi berupa kecepatan mesin dan kecepatan produksi tentu saja memakan waktu lama untuk pengolahan datanya serta memungkinkan terjadinya kesalahan ketika melakukan proses monitoring target produksi yang dilakukan secara periodik dan berkesinambungan.

Dengan melihat kondisi di atas, maka pada penelitian ini dilakukan suatu perancangan dan implementasi sistem CPM otomatis berbasis mikrokontroler. Pada sistem ini digunakan suatu sensor inductive proximityuntuk menghitung jumlah putaran shaft mesin (Tim Schneider Electric, 2014). J umlah putaran ini selanjutnya dipergunakan untuk mengukur kecepatan mesin, kecepatan produksi dan hasil produksi. Penggunaan sensor jenis ini memang belum banyak digunakan secara umum, sehingga perancangan dan realisasi sistem dilakukan dengan melihat data teknis dan karakteristik sensor. Di samping itu, terdapat beberapa faktor lain yang dijadikan pertimbangan untuk menggunakan sensor jenis ini yang disesuaikan dengan kondisi di lapangan (industri) yaitu diantanya kondisi peralatan, kemampuan finasial, alih teknologi dan kemampuan pemeliharaan sistem.

Selain sistem counter, penelitian ini juga bertujuan untuk melakukan perancangan dan implementasi program interfacing (antar muka) dengan Personal Computer (PC). Program ini difungsikan untuk menampilkan semua hasil penghitungan yang dikirimkan dari hasil penghitungan sistem mikroprosessor. Dengan mengirimkan data pada PC maka dimungkinkan untuk dilakukan penyimpanan dan pencetakan data sebagai bahan evaluasi hasil produksi yang telah dicapai.

\section{METODOLOGI IMPLEMENTASI SISTEM}

\subsection{Gambaran Umum Sistem}

Sistem CPM elektronik pada penelitian ini terdiri dari perangkat keras dan perangkat lunak yang dirancang dan diimplementasikan berbentuk sistem modul. Modul perangkat keras sistem ini meliputi modul sensor, modul antar muka input, modul pewaktu, modul pemroses data, modul antar muka output, modul tampilan dan modul catu daya. Dua jenis modul perangkat lunak dirancang dan direalisasikan untuk sistem ini yang difungsikan untuk dua buah perangkat pengolah data yaitu sistem mikroprosessor dan PC. Diagram blok hubungan setiap perangkat keras dan perangkat lunak sistem CPM ini ditunjukkan pada Gambar 1. 


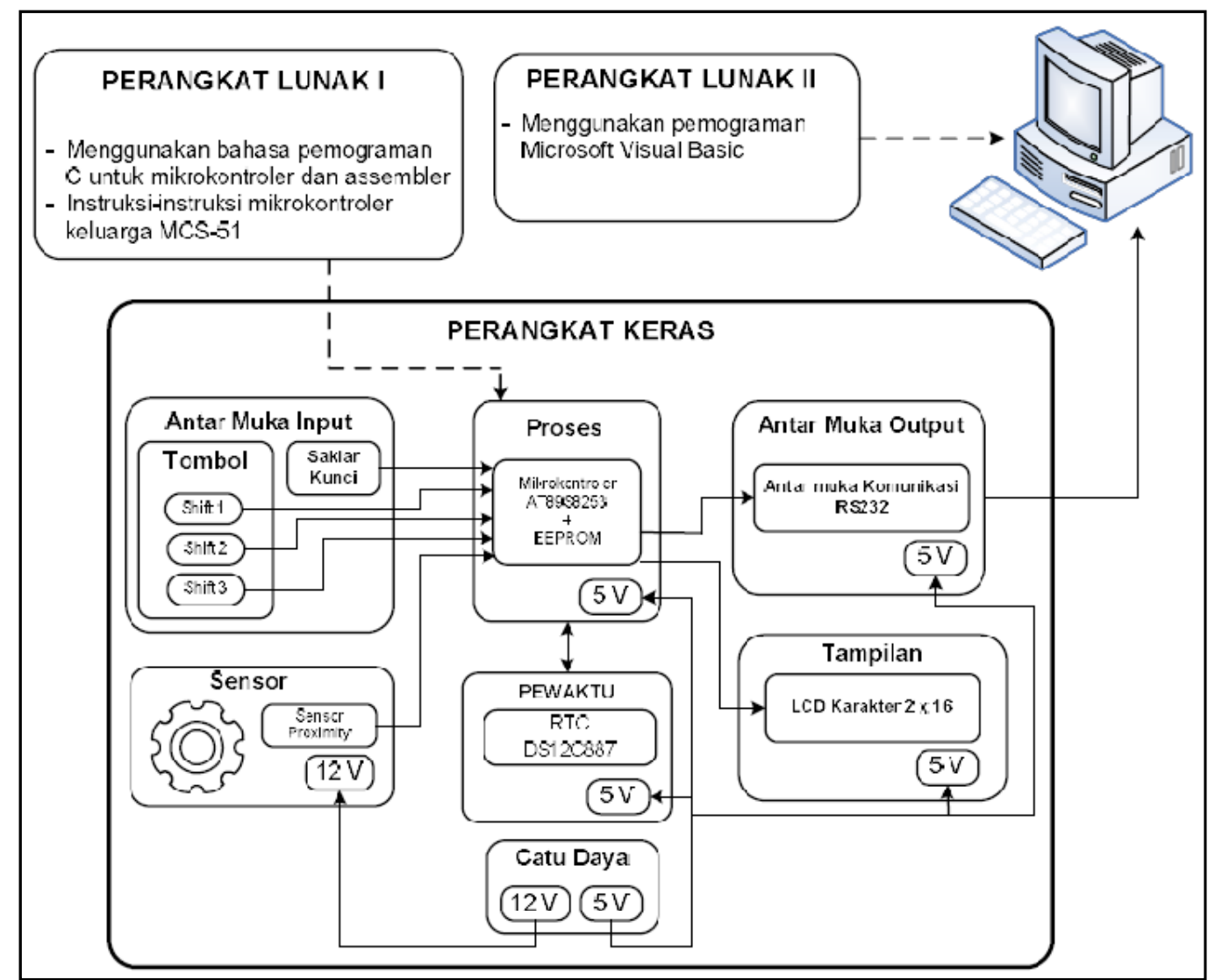

Gambar 1. Diagram blok hubungan perangkat keras dan perangkat lunak untuk sistem Counter Production Monitoring (CPM) berbasis sistem mikroprosessor (mikrokontroler)

Prosedur kerja sistem ini dimulai dari pendeteksian putaran shaft mesin yang terdeteksi selama berputar oleh sensor. Untuk mendeteksi jumlah putaran shaft, digunakan suatu gear encoder berbentuk roda gigi. Jumlah gigi yang terdeteksi oleh sensor ini dihitung oleh modul pemroses sinyal untuk melakukan perhitungan putaran roda gigi dalam satu menit (rotate per minute $=$ RPM). Modul pemroses sinyal ini menggunakan mikrokontroler yang dilengkapi dengan perangkat lunak untuk mengatur seluruh kerja sistem. Jumlah RPM dikalikan dengan keliling shaftmesin akan diperoleh panjang produksi per menit (meter per minute $=$ MPM).

Di dunia industri tekstil khususnya kain tenun katun dan sutera, panjang hasil produksi ini tidak dinyatakan dalam satuan meter, tetapi dalam satuan HANK. Proses konversi satuan meter menjadi HANK dilakukan dengan perbandingan satu HANK setara dengan 768,096 meter. Dikarenakan sistem kerja di industri tekstil berbentuk shift kerja dengan durasi 8 jam kerja per satu shift, maka hasil produksi juga perlu dihitung berdasarkan satu shift kerja. Hal ini untuk melakukan evaluasi performa kerja setiap shift. Pengaturan durasi waktu dikontrol oleh mikrokontroler berdasarkan input dari modul pewaktu.

Kecepatan mesin [RPM], kecepatan produksi [MPM] dan hasil produksi [HANK] ditampilkan pada modul tampilan. Besaran yang ditampilan pada modul tampilan diatur oleh modul antar muka input yang memiliki tiga buah tombol pengaturan. Modul antar muka input ini juga dilengkapi dengan sebuah saklar kunci yang berfungsi untuk melakukan reset jumlah produksi per shift yang dilakukan pada shift kerja sebelumnya. Selain ditampilkan pada 
bagian modul tampilan, semua data hasil penghitungan juga dikirimkan ke PC untuk ditampilkan dan disimpan pada media penyimpanan.

\subsection{Spesifikasi Sistem}

Spesifikasi perangkat keras dan perangkat lunak sistem CPM yang dirancang dan diimplmentasikan pada penelitian ini adalah sebagai berikut:

- Sistem menghitung putaran mesin berdasarkan putaran shaftbagian depan (front rol/).

- Shaft mesin dihubungkan dengan sebuah gear encoder berbahan logam untuk menghitung jumlah mesin.

- Sistem dapat menampilkan tiga besaran pengukuran yaitu kecepatan mesin [RPM], kecepatan produksi [MPM] dan hasil produksi [HANK] untuk setiap shift kerja (per 8 jam) dengan tiga buah tombol pengatur.

- Sistem menggunakan mikrokontroler sebagai pemroses data dan PC sebagai penyimpan data dan penampilan data secara grafis.

- Sistem memiliki fasilitas reset yang hanya dapat diaktifkan oleh petugas tertentu.

- Sistem perangkat keras menggunakan dua buah jenis catu daya yaitu $5 \mathrm{~V}_{\mathrm{DC}}$ dan $12 \mathrm{~V}_{\mathrm{DC}}$.

\subsection{Realisasi Sistem}

Perangkat keras dan perangkat lunak direalisasikan dengan sejumlah komponen elektronik dan bahasa pemograman yang disesuaikan dengan spesifikasi sistem CPM.

\section{a. Perangkat Keras}

\section{a.1. Modul Sensor}

Modul sensor ini berfungsi untuk membaca gerakan mekanik berupa putaran mesin dan mengubahnya menjadi bentuk sinyal pulsa digital.Modul ini terdiri dari gear encoder berbahan logampejal dan sensor proximity switch bertipe induktif yang sangat cocok untuk mendeteksi material berbahan logam. Gear ini dipasang pada shaftmesin bagian depan yang berputar. Lekukan gear encoder dibubut dengan jumlah lekukan lembah sebanyak 10 buah, sehingga memiliki resolusi putaran sebesar 10 pulsa per putaran. Jarak lekukan lembah dengan puncak gear dibuat dengan dimensi $4 \mathrm{~mm}$ agar keluar dari daerah deteksi sensor proximity switch yaitu $\pm 2 \mathrm{~mm}$. Desain gear encoder beserta dengan dimensinya ditunjukkan pada Gambar 2.
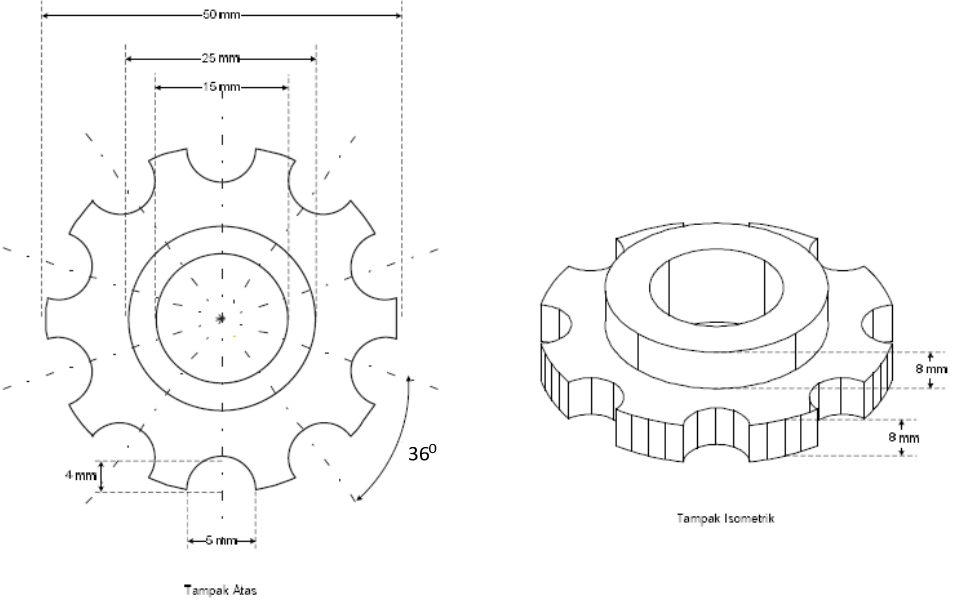

Gambar 2.Desain Gear Encoder dengan bahan logam yang dilihat dari tampak atas (kiri) dan tampak isometrik (kanan) beserta dengan dimensinya. 
Sensor inductive proximity switch ditempatkan berdekatan dengan gear encoder dengan jarak kurang dari $2 \mathrm{~mm}$ agar dapat berinduksi dan menghasilkan pulsa (P) berlogika ' 1 ' jika mendeteksi gigi gear encoder berbahan logam (Zikraniko, 2013). Dikarenakan sensor ini menghasilkan tegangan $12 \mathrm{~V}_{\mathrm{DC}}$ ketika mendeteksi adanya logam maka tegangan ini perlu disesuaikan menjadi $5 \mathrm{~V}_{D C}$ agar diperoleh sinyal pulsa digital.Untuk penyesuaian tegangan ini, sensor dilengkapi dengan sebuah Zener $5.5 \mathrm{~V}$ untuk membatasi tegangan yang dihasilkan.Pada Gambar 3 ditunjukkan rangkaian sensor inductive proximity switch.dengan pembatas tegangan dan gear encoder.

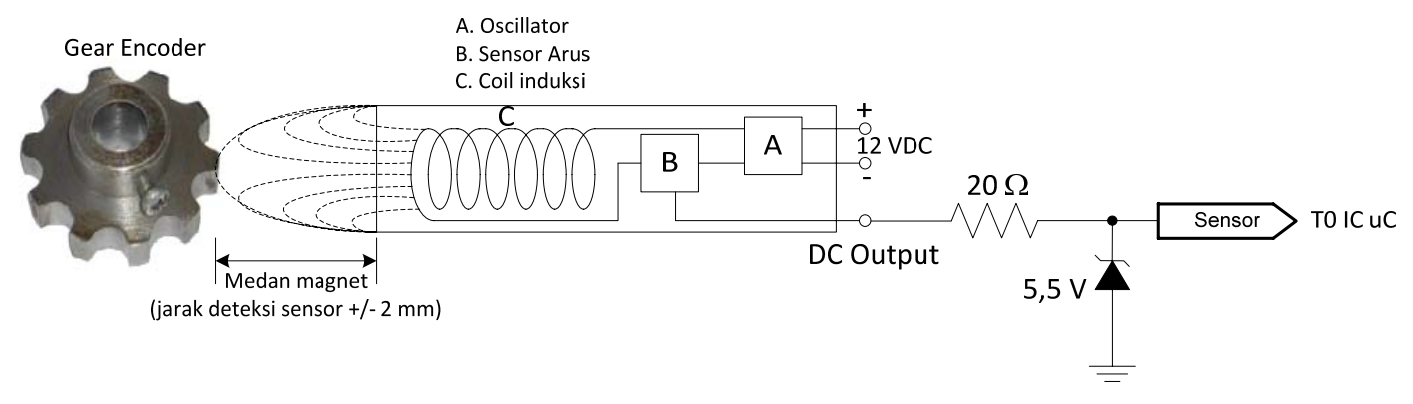

Gambar 3.I mplementasi modul sensor

Dengan mengetahui jumlah lekukan lembah yang juga sama dengan jumlah gigi gear encoder $(n)$ yang berjumlah 10 dan jumlah pulsa $(P)$ berlogika ' 1 ' yang dideteksi dalam suatu interval waktu tertentu (t), maka dapat dihitung kecepatan mesin dalam satu menit [RPM] dengan menggunakan persamaan (Tim IE, 2014):

$$
\text { Kecepatan mesin }[\mathrm{RPM}]=\frac{P}{n} \times \frac{60}{t}
$$

Dalam sistem ini, gigi gear encoder dideteksi dengan interval waktu (t) sebesar 2 detik sekali.Besarnya kecepatan mesin ini digunakan untuk menghitung kecepatan produksi yang merupakan panjangnya kain yang bergulir sepanjang keliling shaft mesin dalam satuan menit.Dikarenakan keliling shaft berbentuk lingkaran maka diameter shaft (D) diperlukan untuk menghitung keliling lingkaran.Dengan diameter shaft sebesar $28 \mathrm{~mm}$ maka kecepatan produksi dapat dihitung dengan persamaan:

Kecepatan produksi[MPM] $=$ keliling shaft $\times$ Kecepatan mesin $=\pi \cdot D \cdot$ Kecepatan mesin

Jadi untuk menghitung hasil produksi dalam satuan HANK per shift ( 8 jam per shift) maka nilai kecepatan produksi dengan satuan meter per menit [MPM] dikonversi menjadi nilai hasil produksi dalam satu shift dengan persamaan

Hasil produksi $\left[\frac{\text { HANK }}{\text { shift }}\right]=$ kecepatan produksi $\left[\frac{\text { meter }}{\text { menit }}\right] \times \frac{1}{768,096}\left[\frac{\text { HANK }}{\text { meter }}\right] \times 60\left[\frac{\text { menit }}{\text { jam }}\right] \times 8\left[\frac{\text { jam }}{\text { shift }}\right]$

\section{a.2. Modul Antar Muka I nput}

Modul antar muka input terdiri dari 3 buah tombol push on untuk menampilkan tiga jenis hasil penghitungan dan sebuah saklar kunci 2 pole untuk melakukan reset tampilan data sebelumnya. Ketiga tombol dan sebuah jalur input dari saklar kunci dihubungkan langsung 
ke setiap pin mikrokontroler yang berbeda. Fungsi ketiga tombol tersebut ditentukan oleh posisi saklar kunci. Jika saklar kunci dalam posisi berwarna hijau, maka fungsi ketiga tombol tersebut yaitu:

- Tombol 1 berfungsi untuk menampilkan kecepatan mesin dalam satuan RPM

- Tombol 2 berfungsi untuk menampilkan kecepatan produksi dalam satuan MPM

- Tombol 3 berfungsi untuk menampilkan hasil produksi dalam satuan HANK per shift

Akan tetapi, jika saklar kunci dalam posisi berwarna merah, maka sistem terlebih dahulu akan menampilkan hasil produksi per shift (per 8 jam kerja). Selanjutnya pada posisi kunci ini, ketiga buah tombol akan berubah fungsi yaitu tombol 1 berfungsi untuk menerima fungsi reset hasil produksi per shift, sedangkan tombol 2 dan tombol 3 berfungsi untuk menolak fungsi reset.

Ketiga tombol bersifat aktif Low ketika ditekan, sedangkan saklar kunci bersifat aktif Low ketika dalam posisi berwarna hijau. Untuk dapat melihat ketiga hasil pengukuran secara langsung jika salah satu dari ketiga tombol ditekan, maka ketiga tombol ini dihubungkan dengan suatu rangkaian logika digital (IC 74LS08) sehingga dapat memberikan fungsi interupsi pada modul pemroses sinyal (INT 1). Rangkaian logika yang dihasilkan berupa fungsi logika AND dari ketiga tombol tersebut. Implementasi modul antar muka input ini ditunjukkan pada Gambar 4.

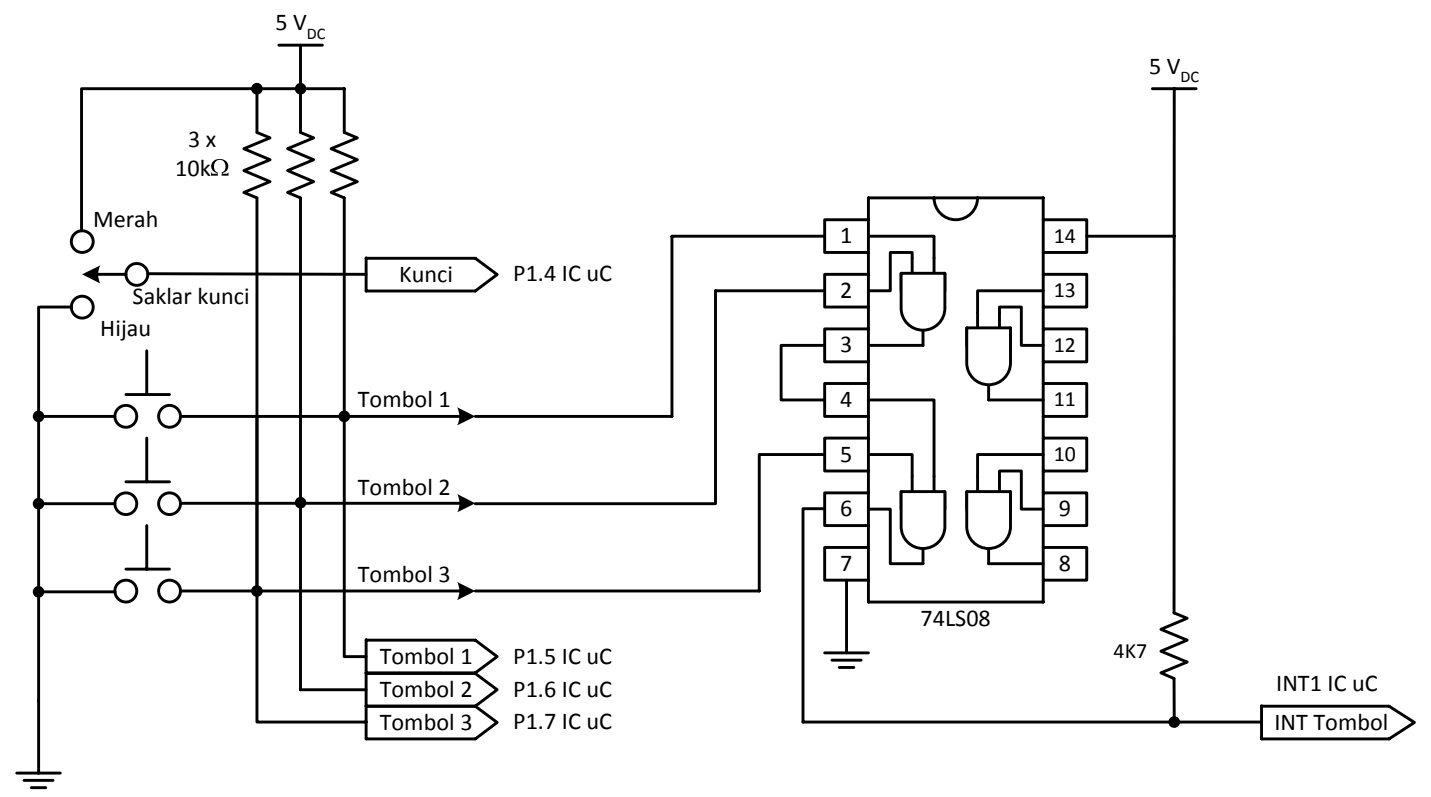

Gambar 4. I mplementasi modul antar muka input

\section{a.3. Modul Pewaktu}

Modul pewaktu menggunakan komponen utama berupa komponen terintegrasi (IC) real time clock (RTC) tipe DS12C887.Modul pulsa eksternal ini berfungsi untuk menghasilkan pulsa dengan frekuensi $1 \mathrm{~Hz}$ yang lebih presisi.Pulsa ini dihubungkan dengan saluran Interrupt modul pemroses data untuk mengontrol penghitungan waktu guna menghitung kecepatan mesin, kecepatan prosuksi maupun hasil produksi per shift.Implementasi rangkaian modul pewaktu ditunjukkan pada Gambar 5. 


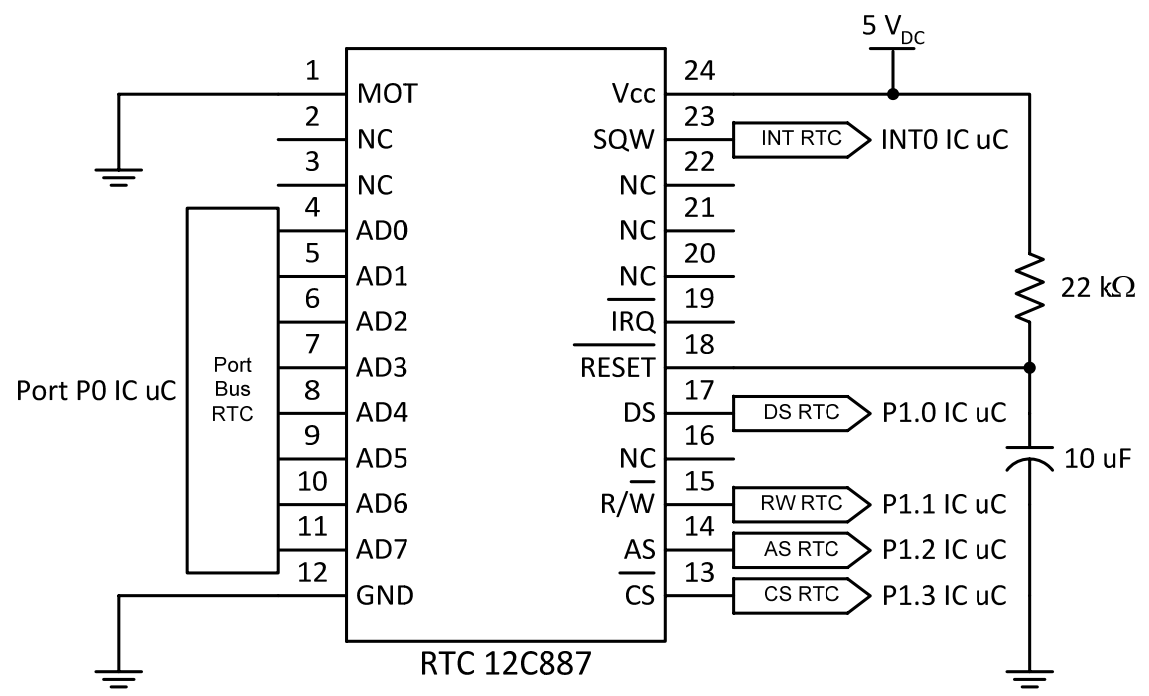

Gambar 5. I mplementasi modul pewaktu dengan komponen utama RTC 12C887

\section{a.4. Modul Pemroses Data}

Modul pemroses data menggunakan mikrokontroler tipe AT89S8253 dengan internal EEPROM 2KByte untuk memproses dan menyimpan semua data sistem. Pada gambar 6 ditunjukkan setiap pin mikrokontroler yang dihubungkan dengan modul-modul lain. Aliran data ini terdiri dari dua jenis yaitu data input dan data output. Pin yang mengarah pada bagian mikrokontroler dinyatakan sebagai data input untuk mikrokontroler.

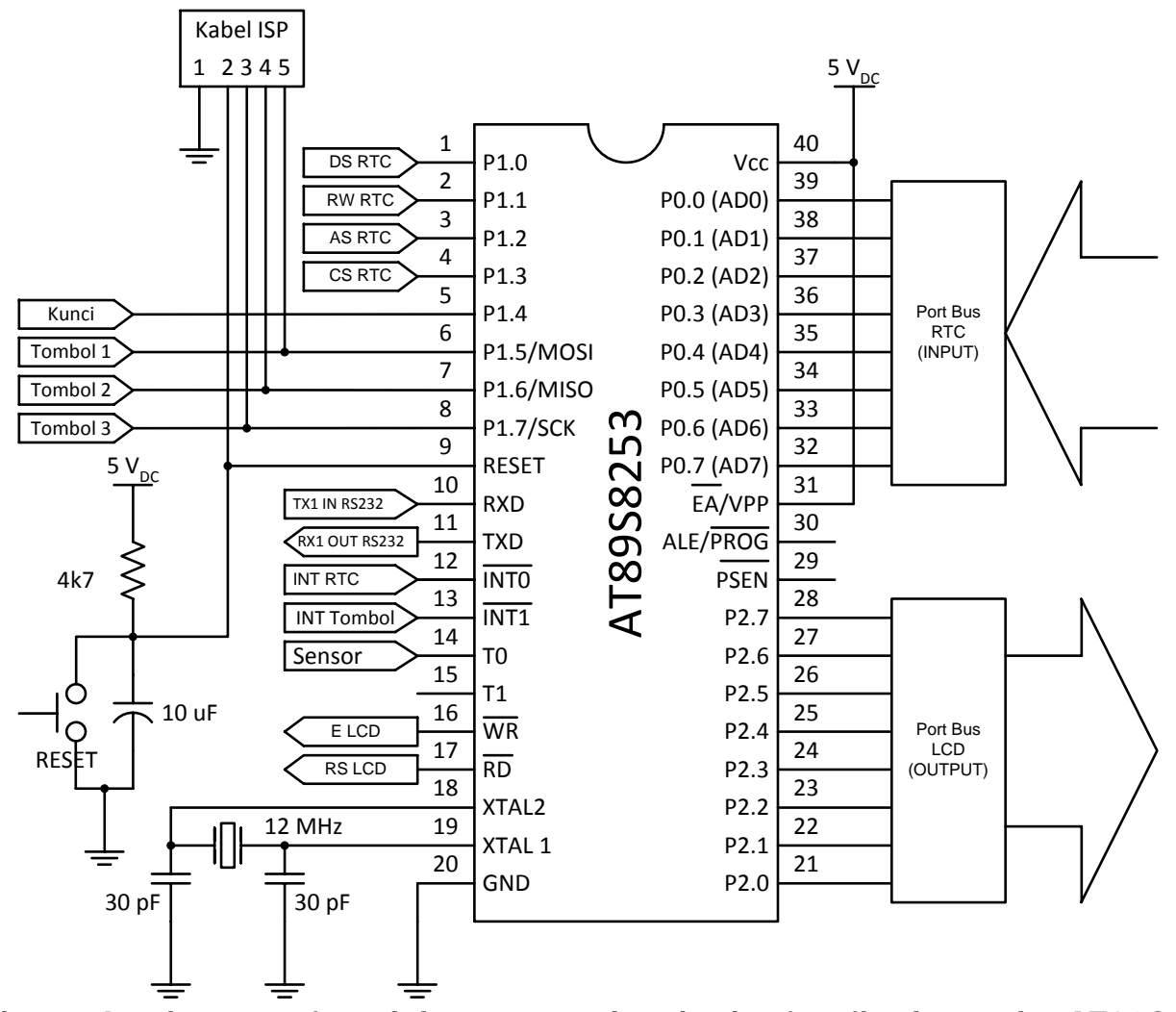

Gambar 6. I mplementasi modul pemroses data berbasis mikrokontroler AT89S8253 


\section{a.5. Modul Antar Muka Output}

Modul antar muka output yang dirancang menggunakan komponen MAX232 untukmelakukan transfer data dari modul pemroses data dengan PC melalui komunikasi serial.Penggunaan komponen MAX 232 ini untuk menhatasi perbedaan level tegangan antara mikrokontroler dengan dengan saluran komunikasi serial pada PC. Kapasitor-kapasitor berpolaritas yang terhubung dengan komponen MAX 232 digunakan sebagai charge pump untuk menaikkan dan menurunkan tegangan output komponen MAX 232. Implementasi modul antar muka output sistem ini ditunjukkan pada Gambar 7.

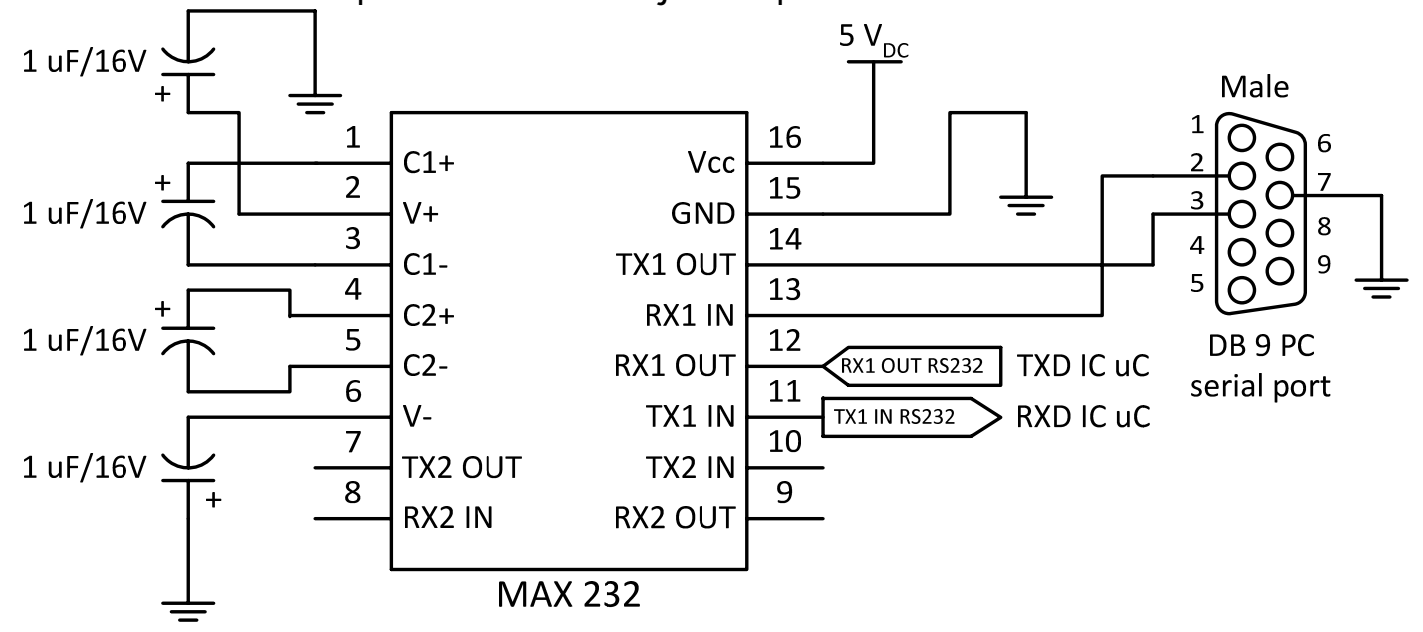

Gambar 7. I mplementasi modul antar muka output untuk transfer data antara modul pemroses data dengan PC melalui komunikasi serial

\section{a.6. Modul Tampilan}

Semua data hasil perhitungan yang terdiri dari kecepatan mesin [RPM], kecepatan produksi [MPM] dan hasil produksi [HANK] dalam satu shift ditampilkan pada sebuah komponen LCD. Modul tampilan LCD yang digunakan untuk sistem ini berupa matriks LCD tipe 2x16 karakter.Pada Gambar 8 ditunjukkan implementasi modul tampilan LCD. 


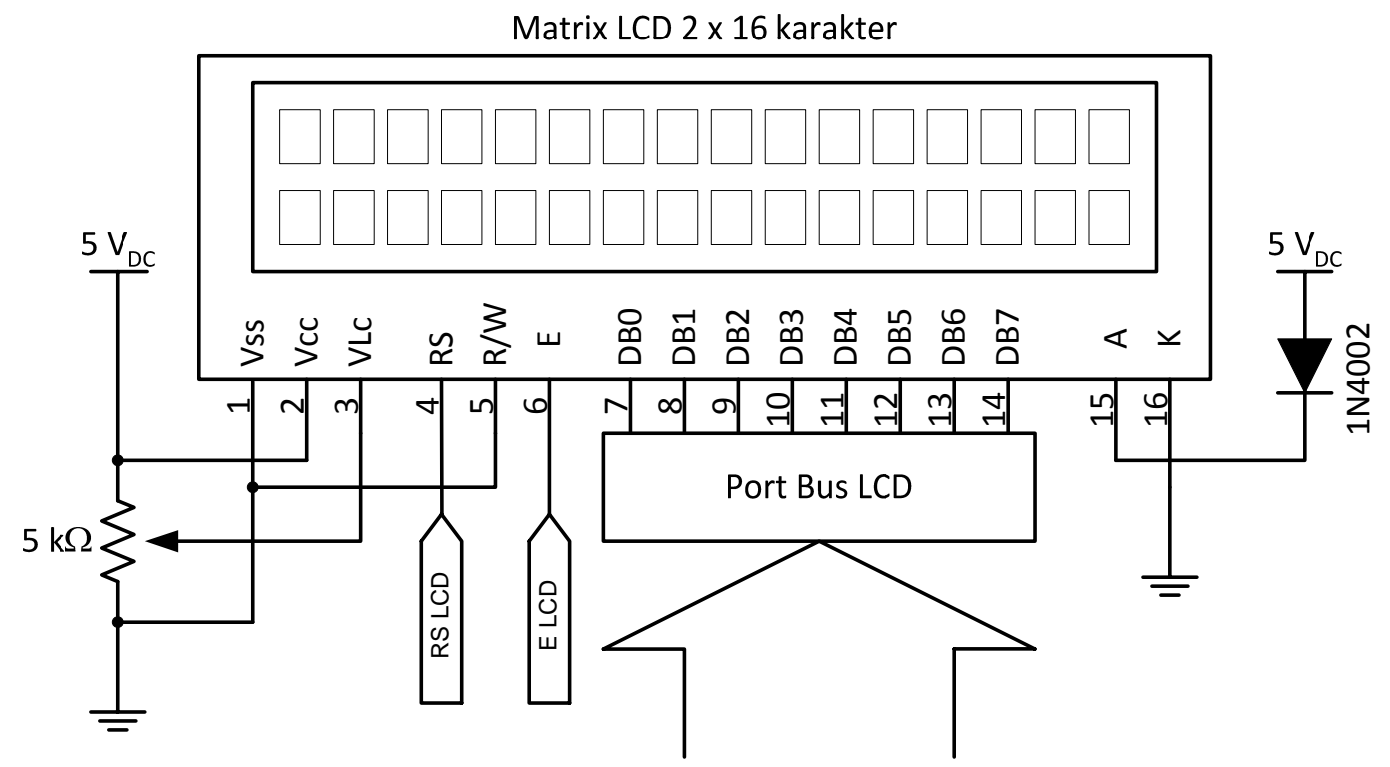

Gambar 8. I mplementasi modul tampilan LCD dengan tipe 2 x 16 karakter

\section{a.7. Modul Catu Daya}

Modul catu daya memiliki dua besaran tegangan yaitu 12 VDC untuk mencatu modul sensor dan 5 VDC untuk mencatu modul-modul sistem lainnya.Modul ini direalisasikan dengan menggunakan sebuah transformator yang dilengkapi dua sistem regulator tegangan agar terhindar dari panas yang berlebihan pada salah satu sistem regulator.Modul catu daya yang direalisasikan pada sistem ini ditunjukkan pada Gambar 9.

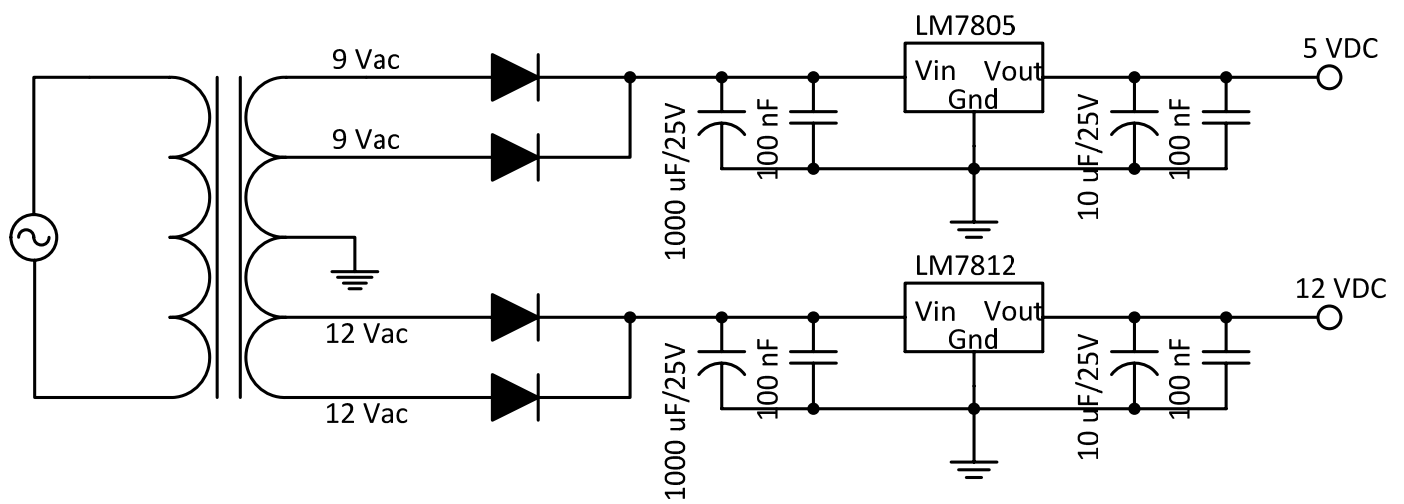

Gambar 9. I mplementasi modul catu daya dua tegangan output $5 \mathrm{~V}_{\mathrm{DC}}$ dan $12 \mathrm{~V}_{\mathrm{DC}}$

\section{b. Perangkat Lunak}

\section{b.1. Perangkat Lunak I}

Perangkat lunak I merupakan program instruksi pada modul pemroses data yang diimplementasikan dengan menggunakan bahasa pemograman $\mathrm{C}$ dan Assembly. Perangkat lunak ini digunakan untuk melakukan pengontrolan semua modul perangkat keras. Diagram alir pemrograman perangkat lunak I ditunjukkan pada Gambar 10. 
Prosedur kerja program pada modul pemroses data ini dimulai dengan inisialisasi sejumlah variabel yang akan digunakan untuk menghitung data, hubungan pin mikrokontroler yang terhubung dengan modul-modul lain baik yang besifat sebagai input maupun output, serta melakukan aktifasi sejumlah fungsi mikrokrontroler seperti timer, interupsi dan komunikasi serial. Selanjutnya sistem mendeteksi posisi kunci pada modul antar muka input. Jika posisi kunci pada posisi hijau, maka program mulai menghitung jumlah pulsa yang diinputkan dari modul sensor sampai dengan program mendeteksi sinyal sinyal waktu dari modul pewaktu (RTC). Data jumlah sensor ini kemudian digunakan untuk menghitung kecepatan mesin [RPM], kecepatan produksi [MPM] dan hasil produksi per shift kerja [HANK per shift].

Seluruh data hasil perhitungan ini kemudian disimpan pada EEPROM mikrokontroler untuk pengambilan data kembali guna ditampilkan pada bagian modul tampilan (LCD) sesuai dengan penekanan ketiga tombol pada modul antar muka input. Setelah data hasil perhitungan ditampilkan, program selanjutnya akan mengirimkan seluruh data tersebut ke PC melalui sistem komunikasi serial. Format pengiriman data yang dikirimkan ke PC ditunjukkan pada Gambar 11. Untuk membedakan setiap data yang dikirimkan, dipergunakan suatu kode pemisah sebagai tanda awal setiap data. Kode S digunakan sebagai tanda awal data kecepatan mesin [RPM], kode M digunakan sebagai tanda awal kecepatan produksi [MPM], kode $\mathrm{H}$ digunakan sebagai tanda awal hasil produksi per shift kerja [HANK per shift] dan kode E digunakan sebagai kode akhir data yang dikirimkan. 


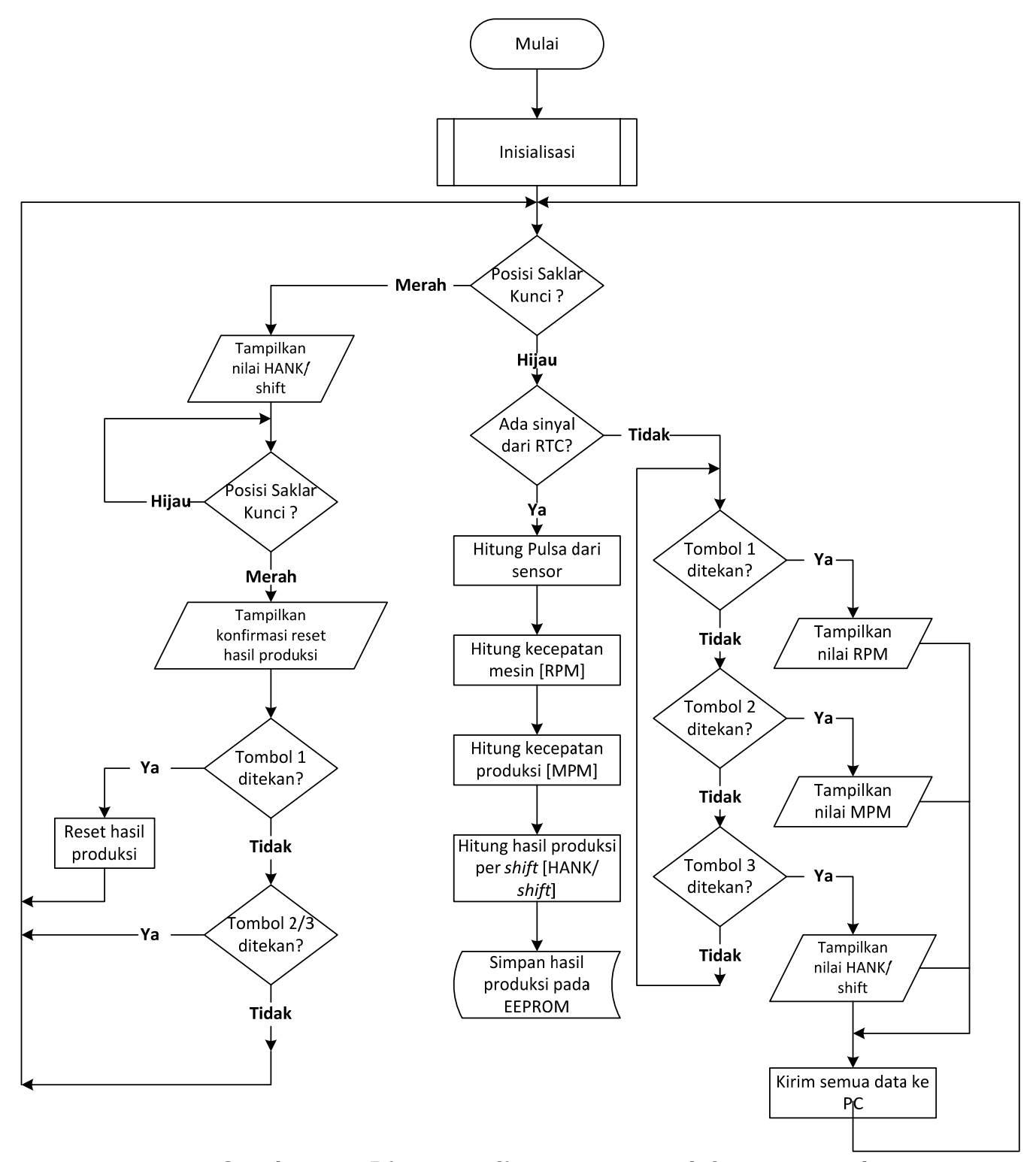

Gambar 10. Diagram alir program modul pemroses data

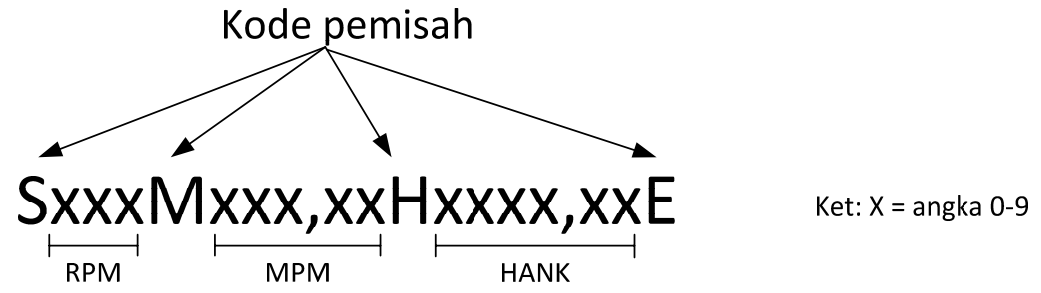

Gambar 11.Format data yang dikirimkan melalui komunikasi serial.

\section{b.2. Perangkat Lunak II}

Perangkat lunak II merupakan program yang dibuat untuk PC dengan menggunakan bahasa pemrograman Microsoft Visual Basic 6.0. Perangkat lunak ini digunakan untuk menampilkan data kecepatan mesin [RPM], kecepatan produksi [MPM] dan hasil produksi [HANK] serta 
untuk melakukan perekaman data agar dapat ditampilkan dalam bentuk grafik. Secara sederhana prosedur program pada PC ditunjukkan dengan diagram alir pada Gambar 12.

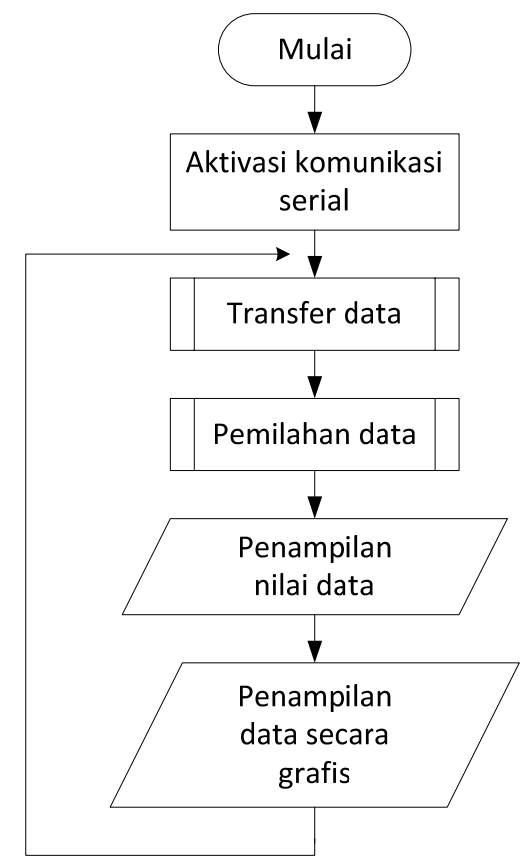

Gambar 12. Diagram alir program pada PC

Program dimulai dengan melakukan aktivasi komunikasi serial yang kemudian dilanjutkan dengan proses transfer data. Setelah data diterima dengan suatu format tertentu, maka data dipilah berdasarkan masing-masing data untuk ditampilkan pada layar monitor PC. Pada program ini, hanya kecepatan mesin [RPM] dan kecepatan produksi [MPM] yang ditampilkan dalam bentuk grafik.Secara lengkap tampilan data pada PC ditunjukkan pada Gambar 13.

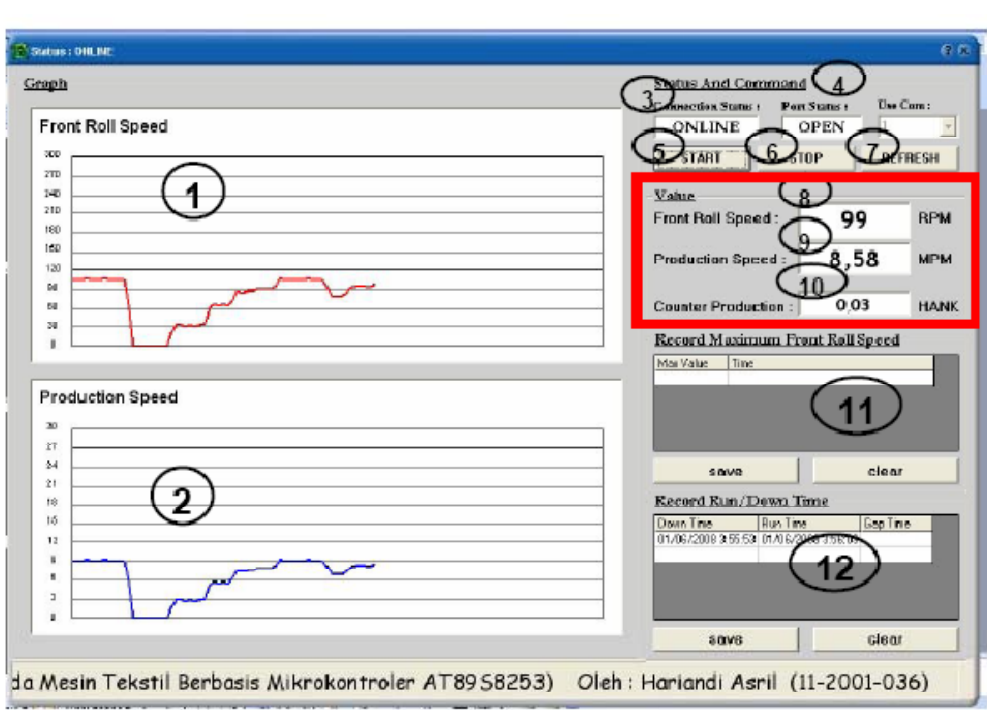

Keterangan :

1. Grafik kecepatan front roll (rpm).

2. Grafik kecepatan produksi (mpm).

3. Status koneksi komunikasi serial counter dengan $\mathrm{PC}$.

4. Status port serial pada PC

5. Tombol membuka port serial $\mathrm{PC}$.

6. Tom bol menutup port serial $\mathrm{PC}$.

7. Tombol me-refresh tampilan.

8. Aktual kecepatan front roll.

9. Aktual kecepatan produksi.

10. Aktual jumlah produksi.

11. Tabel rekaman kecepatan maksimum

12. Tabel rekaman down speed dan run speed.

\section{Gambar 13. Tampilan hasil pengukuran yang diolah oleh perangkat lunak pada PC}




\section{PENGUJ I AN DAN ANALISIS}

Sebelum dilakukan pengujian pada sistem CPM, dilakukan beberapa langkah sebagai persiapan pengujian yaitu diantaranya:

- Pemasangan sumber tegangan 220 AC 1 fasa.

- Pemasangan gear encoder pada shaft front roll.

- Penyetingan jarak sensor dengan gear encoder sebesar $1 \mathrm{~mm}$.

- Memasang dan sinkronisasi komunikasi serial antara sistem CPMdengan PC.

Pengujian sistem PCM ini dilakukan dengan mengukur kegiatan produksi selama 3 shift kerja selama 3 hari. Pengukuran kegiatan produksi yang meliputi kecepatan mesin [RPM], kecepatan produksi [MPM] dan hasil produksi [HANK] dihitung secara otomatis oleh sistem. Sebagai data pembanding maka diukur pula kecepatan front roll menggunakan tachometer digital genggam yang selanjutnya kecepatan produksi [MPM] dan hasil produksi [HANK] dihitung secara manual. Pada pengukuran manual, awal hasil produksi selalu diasumsikan dalam kondisi 0.Berbeda dengan sistem PCM yang mengukur secara kontinyu. Hasil pengujian kegiatan produksi dengan sistem PCM dan secara manual, ditunjukkan secara berurutan pada Tabel 1 dan Tabel 2 .

Tabel 1.Hasil pengujian kegiatan produksi dengan menggunakan sistem CPM

\begin{tabular}{|c|c|c|c|c|c|}
\hline \multirow{2}{*}{ Hari } & \multirow{2}{*}{ Jam Pengambilan } & $\begin{array}{c}\text { Kecapatan } \\
\text { Front Roll }\end{array}$ & $\begin{array}{c}\text { Kecepatan } \\
\text { Produksi }\end{array}$ & $\begin{array}{c}\text { Jumlah } \\
\text { Produksi }\end{array}$ & \multirow{2}{*}{ Total per 8 Jam } \\
\cline { 3 - 5 } & & {$[$ RPM] } & {$[$ MPM] } & [HANK] & [HANK] \\
\hline \multirow{2}{*}{1} & 09.10 & 267 & 23.48 & 0 & \multirow{2}{*}{14.25} \\
\cline { 3 - 5 } & 17.10 & 265 & 23.32 & 14.25 & \\
\hline \multirow{2}{*}{2} & 08.00 & 265 & 23.32 & 42.46 & \multirow{2}{*}{14.08} \\
\hline \multirow{2}{*}{3} & 16.00 & 266 & 23.40 & 56.54 & \\
\hline \multirow{2}{*}{3} & 08.00 & 265 & 23.32 & 168.50 & \multirow{2}{*}{14.06} \\
\hline
\end{tabular}

Tabel 2.Hasil pengujian kegiatan produksi dengan menggnakan tachometer dan perhitungan manual

\begin{tabular}{|c|c|c|c|c|c|}
\hline \multirow{4}{*}{ Hari } & \multirow{4}{*}{ Jam Pengambilan } & & & & \multirow{3}{*}{ Total per $8 \mathrm{Jam}$} \\
\hline & & $\begin{array}{c}\text { KecapatanFront } \\
\text { Roll }\end{array}$ & Kecepatan Produksi & Jumlah Produksi & \\
\hline & & (baca Tachometer) & (Perhitungan manual) & (Perhitungan manual) & \\
\hline & & [RPM] & {$[\mathrm{MPM}]$} & {$[$ HANK $]$} & [HANK] \\
\hline \multirow{2}{*}{1} & 09.10 & 266 & 23.40 & 0 & \multirow{2}{*}{14.6} \\
\hline & 17.10 & 265 & 23.31 & 14.60 & \\
\hline \multirow[b]{2}{*}{2} & 0 & 265 & 2331 & 0 & \multirow[b]{2}{*}{14.57} \\
\hline & 16.00 & 265 & 23.31 & 14.57 & \\
\hline & & & & & \\
\hline \multirow{2}{*}{3} & 08.00 & 264 & 23.22 & 0 & \multirow{2}{*}{14.54} \\
\hline & 16.00 & 265 & 23.31 & 14.54 & \\
\hline
\end{tabular}


Dari kedua tabel di atas dapat dilihat terjadi perbedaan nilai. Hasil analisis dari pengujian sistem counter adalah sebagai berikut:

- Resolusi kecepatan front roll \pm 3 RPM disebabkan penggunaan jumlah gigi encoder sebanyak 10 gigi berdasarkan perhitungan dengan persamaan [1].

- Perbedaan kecepatan front roll mengakibatkan adanya perbedaan pada kecepatan produksi.

- Jumlah produksi yang dihitung secara manual untuk interval 8 jam lebih besar dibandingkan data yang ditampilkan di di LCD dengan rata-rata $\pm 0,38$ HANK. Hal ini disebabkan adanya faktor dopping dimana faktor dopping adalah peristiwa penggantian cone yang menyebabkan terjadi penghentian produksi untuk sementara. Pada perhitungan manual mesin diasumsikan berjalan terus-menerus.

\section{KESI MPULAN}

Beberapa kesimpulan dapat diambil dari proses realisasi dan pengujian sistem, yaitu :

1. Dari hasil pengujian, sistem mampu mengukur kecepatan front roll, kecepatan produksi, dan jumlah produksi dengan resolusi kecepatan $\pm 3 R P M$.

2. Sistem counter dapat bekerja tanpa henti selama $3 \times 24$ jam dengan pengambilan data setiap 8 jam sekali per hari.

3. Dari hasil pengujian sistem, terjadi perbedaan hasil produksi dengan sistem perhitungan manual. Hal ini disebabkan faktor dopping pada sistem perhitungan manual diabaikan

4. Komunikasi data antara modul pemroses data dengan PC telah berjalan dengan baik sehingga data dapat ditampilkan untuk keperluan evaluasi performa kinerja.

\section{DAFTAR RUJ UKAN}

Hidayat, R., Notosudjono, D., Suhendi, D. (2014). Pengaturan kecepatan putaran motor induksi 1 phasa berbasis mikrokontroler ATMega 8535. E-journal Program Studi Teknik Elektro Universitas Pakuan Bogor. Diakses pada tanggal 26 Juni 2014 dari http://ejurnal. unpak.ac.id/download. php?file=mahasiswa\&id=701\&name=RAHMAT\% 20 HIDAYAT\% 20(054108011)\% 20(OK).pdf

Tim Schneider Eelectric. (2014). Telemecanique: Inductive proximity sensors. Diakses pada tanggal 26 J uni 2014 dari http://www.is-com.rufilesphotoelectric_detectors_xs.pdf.

Zikraniko, D. (2013). Rancang bangun mesin penghancur gelas plastic otomatis menggunakan ATMega 8535. E-Jurnal program studi teknik elektro industri vol. 1 no. 3. Diakses dari http://ejournal.unp.ac.id/students/index.php/tei/article/view/882

Tim IE. (2014). Automatic transmission with encoder meter and display, de Kits Application note. Diakses pada tanggal 20 Februari 2008 dari http://www.innovativeelectronics.com/innovative_electronics/download_files/artikel/AN1 3.pdf. 